\title{
The result of the influence for center pivot irrigation machine operations on rain intensity
}

\author{
Delgermaa Lkhagvasuren*, Nuuts Yadamsuren, \\ Otgonkhuyag Balgan and Byambadorj Chagnaadorj
}

School of Engineering and Technology, Mongolian University of Life Sciences, Ulaanbaatar, Mongolia

ARTICLE INFO: Received: 14 Jan, 2021; Accepted: 27 Sep, 2021

\begin{abstract}
The impact of two parameters - the pressure regulator XI at the nozzle and the speed of the machine X2 for the amount of water flow through the sprinkler $(Y, \mathrm{~mm})$ experiment were determined by $8 \mathrm{~mm}$ diameter nozzles. The experiment was carried out in the laboratory of "Design of Irrigation and Equipment" used by "Sprinkler's uniformity distribution measuring equipment" at the School of Engineering and Technology of MULS. In order to determine the rain intensity of low pressure sprinkler nozzle, mathematical statistical methods was used and it was found that the maximum amount of water supplied by the sprinkler nozzle is $1.727 \mathrm{~mm} / \mathrm{min}$ with a maximum pressure of 30 PSI and a minimum speed is $1 \mathrm{~m} /$ min with a minimum flow rate of $0.313 \mathrm{~mm} / \mathrm{min}$. At a pressure regulator value of $20 \mathrm{PSI}$, the speed was a maximum of $3 \mathrm{~m} / \mathrm{min}$.
\end{abstract}

Keywords: Sprinkler; nozzle; pressure regulator; irrigation; rain intensity;

\section{INTRODUCTION}

Many technical and technological works have been carried out since 2004 designed at restoring irrigated agriculture in the country as part of the state policy, At the end of 2019, Mongolia had 57.1 thousand hectares of lands for irrigation, of which 54.1 thousand hectares were irrigated. This accounts for 12.5 per cent of the country's total arable land. 92.0 per cent of all the farmers in the country irrigate their fields by simple methods, 7.1 per cent use sprinkler equipment for irrigation, and the level of mechanization has reached 32.2 per cent. Particularly, large sprinklers, such as Valmont (Walley), Lindsay (Zimmatic, Greenfeeld), TL
(USA), 2iE (France), which have center pivot or have linear move are being used besides irrigation systems from companies such as Bauer and Beinlich from Germany and Austria, as well as portable small-scale irrigation devices made in China, such as FRP50, FRP65, FRP76, FLP76-50, FLP102-65, FLP127-76 are being widely used in the country. In future, the efficiency of sprinkler irrigation can be enhanced by ensuring uniform distribution of water supplied by area, and by determining the quaesitum of sprinkler nozzles, uniform distribution of water supplied by irrigation machines, and water evaporation losses $[4,5,6]$.

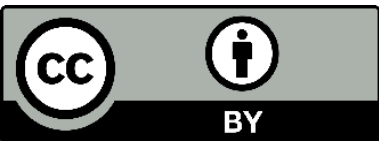

The Author(s). 2021 Open access This article is distributed under the terms of the Creative Commons Attribution 4.0 International License (https://creativecommons.org/licenses/by/4.0/), which permits unrestricted use, distribution, and reproduction in any medium, provided you give appropriate credit to the original author(s) and the source, provide a link to the Creative Commons license, and indicate if changes were made. 


\section{MATERIALS AND METHODS}

The following experiments were performed under laboratory conditions.

Valley LEN type low energy nozzle number 8 is selected and measurements were made by placing the nozzle at a height of 2

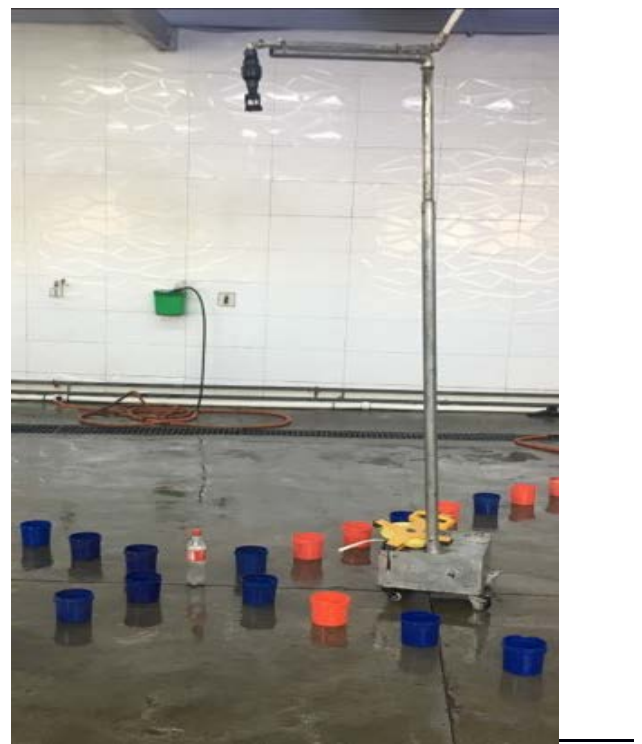

Figure 1. Sprinkler's distribution radius measuring equipment

1-wheel, 2- base, 3-vertical support, 4- switch, support, 5-sprinkler, 6, 8-water pipe, 7-valve, 9- pump, 10- manometer

The measurement was made by adjusting the pump pressure of the laboratory equipment to 45 PSI or 3 bar. The nozzle was rotated evenly at 100,75 and 50 per cent speeds respectively, 40 measuring catch in the form of 4 rows of beams at an angle of $30^{\circ}$ were placed within the spray radius of the nozzle [4]. The rim of the measuring catch was $11 \mathrm{~cm}$ in diameter and $9.5 \mathrm{~cm}$ high [2]. At the moment of continuous transfer of the nozzle, the amount of water collected in the container was weighed. Measurements were made of the amount of water sprayed by the sprinkler nozzle, a graph of the spray nozzle uniformity was established, and the appropriate relationship between them was determined (as per the ANSI.ASAE S436.1 DEC01 standard).

The dependence of the outcome of the irrigation operation or the amount of irrigation on these factors can be expressed as a function and the factors influencing the experiment are considered as follows.

This includes:

$\mathrm{Xi}$ - Manageable (input) factors during the test:

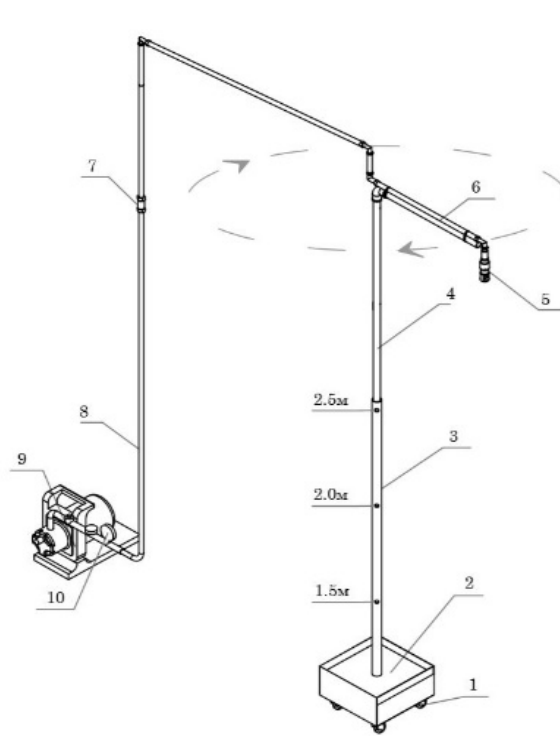

meters on the laboratory equipment. Three different pressures were applied in the pressure regulator on the nozzle: 10 PSI, 20 PSI and 30 PSI $[6,8]$.

X1 - Pressure on nozzle, PSI

$\mathrm{X} 2$ - Last span speed or sprinkler testing speed, $\mathrm{m} / \mathrm{min}$

$\mathrm{Zi}$ - Possible controllable parameters during the test:

Z1 - Sprinkler nozzle diameter,

Z2 - Sprinkler water distribution radius, in $\mathrm{cm}$

$\mathrm{Pi}$ - Notcontrollable during the test:

P1 - Weather condition (wind speed, temperature, air humidity etc.)

P2 - Evaporation

Yi - Identifiable indicators of performance during the test:

Y1 - Sprinkler water distribution

Depending on whether the input parameters or factors affecting the operation of the technology can be controlled during the experiment, the mathematical model was grouped into manageable $\mathrm{Xi}$, controllable $\mathrm{Zi}$, and uncontrollable Pi factors.

$$
Y=f\left(X_{i}, Z_{i}, P_{i}\right)
$$

A rotatable test design method was used to perform the multi-factor experiment in order 
to calculate how each factor would affect the irrigation operation and to take a decision of ways to change it.
The names of the influencing factors and the range of the variables during the test are expressed as follows:

Table 1. Variable range and name of factors influencing irrigation during the experiment

\begin{tabular}{|c|c|c|c|c|c|c|}
\hline \multicolumn{3}{|c|}{ Factor } & \multicolumn{3}{|c|}{ Factor level } & \multirow{3}{*}{$\begin{array}{c}\text { Variable } \\
\text { repair }\end{array}$} \\
\hline \multirow{2}{*}{ Name } & \multicolumn{2}{|c|}{ Notation } & \multirow{2}{*}{ Bottom } & \multirow{2}{*}{$\begin{array}{l}\text { Central } \\
\text { (basic) }\end{array}$} & \multirow{2}{*}{ Top } & \\
\hline & Letter notation & Real value & & & & \\
\hline Pressure regulator - $X_{1}$, PSI & $\mathrm{p}$ & $\mathrm{X}_{1}$ & -1 & 0 & +1 & 10 \\
\hline Speed of machine $-\mathrm{X}_{2}, \mathrm{~m} / \mathrm{min}$ & $\mathrm{t}$ & $\mathrm{X}_{2}$ & -1 & 0 & +1 & 1 \\
\hline \multicolumn{2}{|l|}{$\mathrm{X}_{1}$ ба $\mathrm{X}_{2}$ Factors } & $\begin{array}{l}\text { Normalized } \\
\text { value }\end{array}$ & - & 0 & + & \\
\hline
\end{tabular}

The above factors can be changed during the experiment.

Table 2. Experiment conditions

\begin{tabular}{|c|c|c|c|c|c|c|}
\hline \multirow[t]{2}{*}{ Factors } & \multicolumn{5}{|c|}{ Factors changing value } & \multirow{2}{*}{$\begin{array}{c}\text { Changing } \\
\text { interval }\end{array}$} \\
\hline & -1.414 & -1 & 0 & +1 & +1.414 & \\
\hline Pressure regulator - $\mathrm{X}_{1}$, PSI & 5.86 & 10 & 20 & 30 & 34.14 & 10 \\
\hline Speed of machine $-\mathrm{X}_{2}, \mathrm{~m} / \mathrm{min}$ & 0.586 & 1 & 2 & 3 & 3.414 & 1 \\
\hline
\end{tabular}

\section{RESULTS AND DISCUSSION}

The experiment was performed using the central composite orthogonal planning method, for a total of 13 experiments. During one experiment, 40 catch cans were collected and their average values were considered as one repetition [2].

As a result of the experiment, the following mathematical analyzes were performed. First, the Stiyudyentyn criteria was checked to determine the alternatives for its distinctive values and then dispersion testing criteria Kokhryeny was used to determine any kind of variance test [1]. Since the variances are homogeneous, the second value of the regression equation is written as follows:

$$
Y_{T}=b_{0}+b_{1} \cdot x_{1}+b_{2} \cdot x_{2}+b_{3} \cdot x_{1} \cdot x_{2}+b_{4} \cdot x_{1}^{2}+b_{5} \cdot x_{2}^{2}
$$

From here, irrigation water intensity (Y, $\mathrm{mm} / \mathrm{min}$ ) depending on the two technological parameters, the water pressure from the nozzle and the speed of irrigation machine, the coded phase expression of the equation was determined in the following manner.

$$
Y_{T}=1.253+0.313 \cdot x_{1}-0.270 \cdot x_{2}-0.099 \cdot x_{1} \cdot x_{2}+0.022 \cdot x_{1}^{2}-0.285 \cdot x_{2}^{2}
$$

The above equation can represent the experimental results.

Converting the encoded value of an equation to a real value in the following form is expressed as follows:

$$
\begin{aligned}
Y_{T}=1.253+ & 0.313 \cdot\left(\frac{X_{1}-20}{10}\right)-0.270 \cdot\left(\frac{X_{2}-2}{1}\right)-0.099 \cdot\left(\frac{X_{2}-20}{10}\right) \cdot\left(\frac{X_{2}-2}{1}\right)+0.022 \cdot\left(\frac{X_{1}-20}{10}\right)^{2} \\
& -0.285 \cdot\left(\frac{X_{2}-2}{1}\right)^{2}
\end{aligned}
$$

Here, the variable range of the equation factors is as follows.

Rain intensity: $Y_{T}>2.3 \mathrm{~mm} / \mathrm{min}$

Pressure regulator of the nozzle: $X_{l}=10-30 \mathrm{PSI}$

Speed of irrigation machine: $X_{2}=1.0-3.8 \mathrm{~m} / \mathrm{min}$.

After converting the encoded value of the regression equation to the real value, the equation takes the following form: 


$$
Y_{T}=2.419+0.0313 \cdot X_{1}-0.270 \cdot X_{2}-0.0099 \cdot X_{1} \cdot X_{2}+0.00011 X_{1}^{2}-0.1425 \cdot X_{2}^{2}
$$

From the equations obtained from the above experiments, it can be seen that the amount of water supplied for irrigation will not exceed the norm for water sprayed on the machine if the settings are adjusted within the variable range of factors. In other words, the irrigation intensity does not adversely affect the soil or exceed the set norm in any of the regimes. For example, the maximum amount of water supplied $(1.727 \mathrm{~mm} / \mathrm{min})$ is at maximum pressure (30 PSI) and the minimum flow rate (1 $\mathrm{m} / \mathrm{min})$ is at the minimum value $(0.313 \mathrm{~mm})$ at the base value of the pressure setting (2 0 PSI),

\section{CONCLUSIONS}

The results of the experiment show that the general pattern is maintained as the irrigation speed decreases with increasing machine speed and the irrigation regime increases with increasing nozzle water pressure. Here:

1. However, when the nozzle pressure is increased to 30 PSI ( 2 bar) and the speed is slowed down $(1 \mathrm{~m} / \mathrm{min})$, the pressure (30 PSI) and speed $(3 \mathrm{~m} / \mathrm{min})$ are 56 per cent lower than at high speeds.

2. Mainly the nozzle a LEN, it usually operates at 10 PSI. Therefore, when choosing

\section{REFERENCES}

1. Avdai. Ch., Enkhtuya. D., (2019). "Methodology for conducting research". Mongolian University of Science and Technology, Handbook, Ulaanbaatar. pp. 182-207.

2. ANSI.ASAE S436.1. (DEC01). “Test Procedure for Determining the Uniformity of Water Distribution of Center Pivot and Lateral Move Irrigation Machines Equipped with Spray or Sprinkler Nozzles”. pp. 3-5.

3. Bazarsad. Ya., Enkhbat. P., (1998). "Probability Theory and Mathematical-Statistical Handbook”, Ulaanbaatar, 1998, pp. 69-85. when the transition speed is at its maximum (3 $\mathrm{m} / \mathrm{min}$ ).

Russian researcher A. S. Stanko determined a maximum rain intensity of 5.2 $\mathrm{mm}$ on the Volzhanka, or optimal speed for moving into the machine to the field was 0.58 $\mathrm{km} / \mathrm{h}(9.6 \mathrm{~m} / \mathrm{min})$. Comparing the results of this study with the results of their own experiments, the difference in rain intensity was $0.44 \mathrm{~mm}$ and the speed of machine was $0.1 \mathrm{~m} / \mathrm{min}$. This is shown by such factors as the climatic conditions of the region and the utilization of irrigation machine and the environmental conditions.

the speed of the sprinkler Valley 8000 to provide the irrigation norm, it is adjusted between 100 per cent and only 10-20 per cent, and usually operates at a pressure of 10 PSI, which is suitable for sandy soils planted with potatoes.

Acknowledgements: We would like to thank the students of Hydromechanical Engineering courses, the staff of "New Crop" LLC, Khushaat soum, Selenge aimag, and agronomist B. Erdenebaatar for their assistance in conducting this research.

4. Danny. H., Rogers, (2016). “ Performance of Center Pivot Irrigation Systems”, Kansas State University.

5. Khalid Adel Abdelrazaq, (2014). "Improving The Performance of Center Pivot Irrigation System. Journal of Engineering and Development, Vol.18, No.4, ISSN 1813-7822.

6. Sabah Almasraf, Jennifer Jury and Steve Miller, (2014). "Field evaluation of center pivot sprinkler irrigation systems”, Department of Biosystems and Agricultural Engineering Michigan State University. 
7. “Valley Classic Control Panel” (2019). 0997335_G.Valmont Industries, Valley NE68064 USA. p. 33.

8. Wenting. Han and Pute. Wu., (2011). "Evaluation model development for sprinkler irrigation uniformity based on catch can data", African Journal of Biotechnology, Vol.10 (66), pp. 14796-14802, 26 October, ISSN16845315.2011 